\title{
Differences Research of Particles between Line Smoke and Lampblack
}

\author{
Cailin Zhang ${ }^{1, \mathrm{a}, *}$, Fengwen Wang ${ }^{1,2, \mathrm{~b}}$ and Shuyun Yang ${ }^{1,2,3, \mathrm{c}}$ \\ ${ }^{1}$ School of Resources and Environment, Anhui Agricultural University, 130 West Changjiang \\ Road, Hefei 230036, Anhui, China \\ ${ }^{2}$ Hefei Scientific Observing and Experimental Station of Agro-Environment, Ministry of \\ Agriculture, P.R. China, Hefei 230036, China \\ ${ }^{3}$ Jumotang ink industry co., LTD, huangshan road no. 311, Shexian, Huangshan city, Anhui \\ Province, China \\ a2415051107@qq.com \\ bwfw2008@ahau.edu.cn \\ cyangshy@ahau.edu.cn
}

\begin{abstract}
In this paper, differences of the particle size between the pine smoke powders and lampblack powders were studied. The results showed that the particle spectrum of the pine smoke powders was unimodal distribution, while it was bimodal for the tung lampblack powders. The average particle size, volume of lampblack powders were about $1 / 3$ and $3 \%$ of the pine smoke powders, respectively. But the specific surface area of lampblack particles was 5 times more than the pine smoke particles, which revealed the fact that the lampblack powders were more exquisite than the pine smoke powders .
\end{abstract}

\section{Introduction}

Hui ink-stick, ranks in the second of China's "Four Treasures for Calligraphy" , embodies lots of effort and sweat of many practitioners, it is very important in the development and spread of traditional Chinese culture[1-6]. The main material for ink making is soot, smoke powder particles of incompletely burned pine or vegetable oil $[7,8]$. But during mass production of ink, pine forest was seriously damaged as pines live a long growing season[9, 10]. While vegetable oil such as tung oil, rapeseed oil, soybean oil, etc. with short growing season are ecological materials[11]. In this paper, taking the pine smoke powders and tung lampblack powders as examples, differences of the particle size and the feasibility of using lampblack to replace the pine smoke were studied based on the particle size distribution of both ink making materials.

\footnotetext{
*Corresponding author:2415051107@qq.com
} 


\section{Instrument and Material}

In the study, BT-9300H laser particle size analyzer was used. The pine smoke powders and lampblack powders for experiment were the products of Jumotang ink industry co., LTD. And the distribution of particle spectrum was analyzed by taking $0.1 \mathrm{~g}$ powders of each materials to put in the laser particle size analyzer.

\section{Results Analysis}

\subsection{Particle Spectrum Distribution of the Pine Smoke Powders}

Results of the particle spectrum distribution of the pine smoke powders showed that the particle size ranged from 0.361 to $84.95 \mu \mathrm{m}$, mean volume diameter was $21.14 \mu \mathrm{m}$, mean area diameter was $9.461 \mu \mathrm{m}$, mean length diameter was $2.331 \mu \mathrm{m}$, median diameter was $19.11 \mu \mathrm{m}$, specific surface area was $234.8 \mathrm{~m}^{2} / \mathrm{kg}$, the particle spectrum was unimodal distrbution and the peak was seen near $22 \mu \mathrm{m}$ (figure 1). The particle size was relatively concentrated, the size from 21.12 to $23.51 \mu \mathrm{m}$ accounted for $6.24 \%$ of the total particles, and the size from 17.05 to $32.41 \mu \mathrm{m}$ was the main composition of the pine smoke particle size which accounted for $35.8 \%$ of the total.

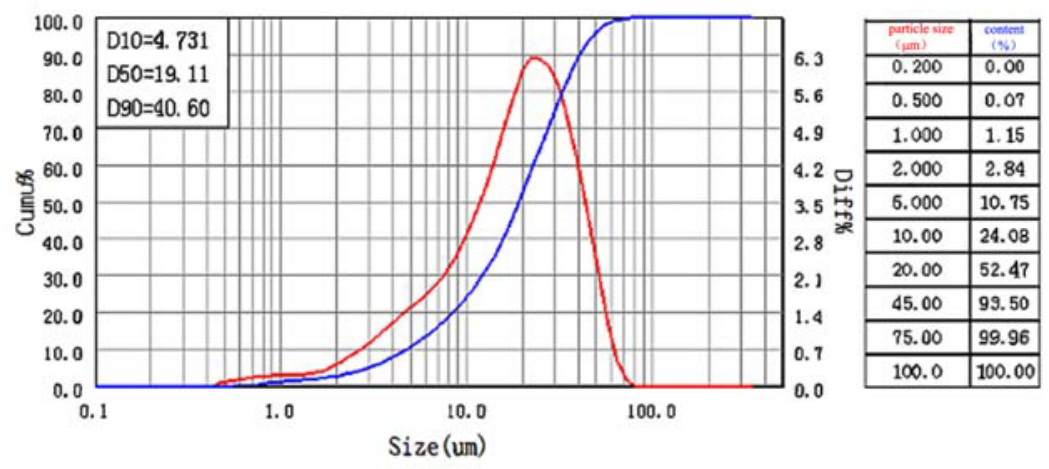

Fig. 1 particle size of the pine smoke powders

\subsection{Particle Spectrum Distribution of the Tung Lampblack Powders}

Results of particle spectrum distribution of the tung lampblack powders were shown in figure 2. The particle size of the lampblack powders ranged from $0.100 \mu \mathrm{m}$ to $68.58 \mu \mathrm{m}$, and size less than $0.100 \mu \mathrm{m}$ couldn't be detected since it was beyond the minimum testing limit of the laser particle size analyzer. Even existed, the proportion of particles less than $0.100 \mu \mathrm{m}$ should be very small as size from $0.100 \mu \mathrm{m}$ to $0.111 \mu \mathrm{m}$ in diameter accounted for only $0.03 \%$ of the total. 

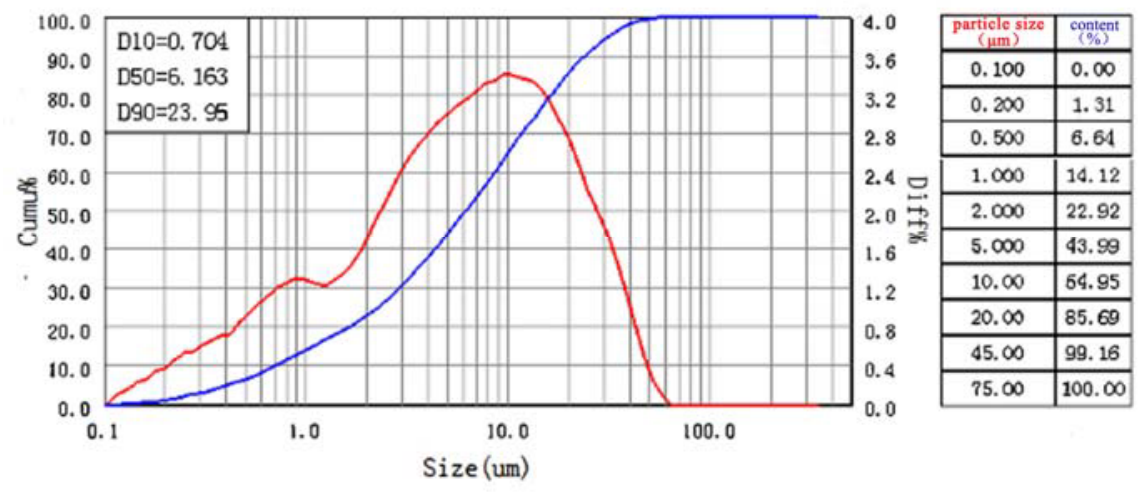

Fig. 2 particle size of lampblack powders

\subsection{Differences Between the Smoke Powders of Pine and Lampblack}

Results of the particle spectrum distribution of the lampblack powders showed that the mean volume diameter was $9.625 \mu \mathrm{m}$, mean area diameter was $1.873 \mu \mathrm{m}$, mean length diameter was $0.401 \mu \mathrm{m}$, and median diameter was $6.163 \mu \mathrm{m}$, which revealed that the average median particle size was about $1 / 3$ of the pine smoke powders, and the volume of lampblack powders was only $3 \%$ of the pine smoke powders, which was much smaller than the pine's. However, it was opposite that the specific surface area of the lampblack was 5 times more than the pine's compared to the differences of volume. The specific surface area of the lampblack was $1186 \mathrm{~m}^{2} / \mathrm{kg}$. There were significant differences from the pine's spectrum. The particle spectrum distribution showed that the particle size of lampblack had double peaks appeared near $0.9 \mu \mathrm{m}$ and $9.5 \mu \mathrm{m}$, respectively. And the particles near peaks were much less than the pine's. Size of particles from 0.850 to $0.947 \mu \mathrm{m}$ around peak 0.9 $\mu \mathrm{m}$ accounted for $1.3 \%$ of the total particles, and particles from 8.970 to $9.983 \mu \mathrm{m}$ near peak $9.5 \mu \mathrm{m}$ accounted for $3.41 \%$, hence the lampblack particles near peaks were much less than the pine particles accounted for $6.24 \%$. Results above suggested that the lampblack particles were highly dispersed and more exquisite than the pine smoke particles.

\section{Conclusions}

Research of the paper concluded that the particle size of tung lampblack had more complex structure than pine particles since the size peaks in diameter of the pine smoke powders appeared in $22 \mu \mathrm{m}$ but the peaks of the lampblack appeared in 0.9 and $9.5 \mu \mathrm{m}$, respectively. And the lampblack powders were more exquisite than the pine smoke powders since the average particle size, volume of lampblack powders were about $1 / 3$ and $3 \%$ of the pine smoke powders, respectively, while specific surface area of lampblack particles was 5 times more than the pine smoke particles. As a whole, it was difficult for the lampblack material to replace the pine smoke powders in the production as there existed significant differences between the pine smoke powders and the tung lampblack powders. 


\section{Acknowledgements}

I deeply appreciate teacher Yang, my supervisor, who walked me through the process of the writing. Without his consistent and illuminating instruction, the paper wouldn't have been so well. This work was Carried out as part of project 11007230, "Research of advanced protective development for traditional industry of Hui ink and She inks tone", for which funding is gratefully acknowledged.

\section{References}

1. H.Y. Chi, Research of print plate scheme of Chinese ink mold, J. Shanghai art \& crafts, 2009, No. 01, pp. 64-65.

2. Z.W. Jiang, Arise of Hui ink-stick, J. Jianghuai culture history, 2011, No. 01, pp. 148-159.

3. J.F. Meng, G. Li, Cultural connotation and folk meaningin the decoration of Hui ink-stick, J. Beauty and age, 2015, No. 01, pp. 50-51.

4. G.F. Shi, Carving arts of Huizhou Ink Mold, Mountain Huangshan publishing house, 1985.

5. Y.S. Wen, Brief discription of history and implement process of Hui ink-stick, J. Modern vocational education, 2015, No. 03, pp. 92-94.

6. Z.P. Zhang, The aesthetic value of Hui ink mode and ink spectral art, J. Journal of Huangshan university, 2012, Vo1.14, No. 02, pp. 9-32.

7. J.G. Li, M.Z. Zhang, Ink making in ancient China, J. Stele forest archives, 2001, No. 00, pp. 243-252.

8. F. Nan, Hui ink-stick in passing, J. Chinese handicraft, 2015, No. 02, pp. 50-51.

9. Z.J. Jin, The second of China's four treasures---ink, J. Chinese medicine culture, 2006, No. 4, pp. 21-26.

10. G.Z. Chao, Mojing, BC388.

11. T. Chen, The manufacturing of inkstick in the Song Dynasty, J. Journal of Langfang Teachers University（Social Sciences Edition）, 2014, Vol. 30, No. 5, pp. 62-65. 